\title{
Genetic basis of transferase-deficient galactosaemia in Ireland and the population history of the Irish Travellers
}

\author{
Miriam Murphy ${ }^{1}$, Brian McHugh ${ }^{1,3}$, Orna Tighe ${ }^{3}$, Philip Mayne ${ }^{1}$, Charles O’Neill ${ }^{1}$, \\ Eileen Naughten ${ }^{2}$ and David T Croke ${ }^{3}$ \\ ${ }^{1}$ Department of Pathology and ${ }^{2}$ Metabolic Unit, The Children's Hospital \\ ${ }^{3}$ Department of Biochemistry, The Royal College of Surgeons in Ireland, Dublin, Republic of Ireland
}

\begin{abstract}
Transferase-deficient galactosaemia, resulting from deficient activity of galactose-1-phosphate uridyltransferase (GALT), is relatively common among the Travellers, an endogamous group of commercial/industrial nomads within the Irish population. This study has estimated the incidence of classical transferase-deficient galactosaemia in Ireland and determined the underlying GALT mutation spectrum in the Irish population and in the Traveller group. Based upon a survey of newborn screening records, the incidence of classical transferase-deficient galactosaemia was estimated to be 1 in 480 and 1 in 30000 among the Traveller and nonTraveller communities respectively. Fifty-six classical galactosaemic patients were screened for mutation in the GALT locus by standard molecular methods. Q188R was the sole mutant allele among the Travellers and the majority mutant allele among the non-Travellers $(89.1 \%)$. Of the five non-Q188R mutant alleles in the non-Traveller group, one was R333G and one F194L with three remaining uncharacterised. Anonymous population screening has shown the Q188R carrier frequency to be 0.092 or 1 in 11 among the Travellers as compared with 0.009 or 1 in 107 among the non-Travellers. The Q188R mutation was shown to be in linkage disequilibrium with a Sac I RFLP flanking exon 6 of the GALT gene. This represents the first molecular genetic description of classical transferase-deficient galactosaemia in Ireland and raises intriguing questions concerning the genetic history of the Irish Travellers.
\end{abstract}

Keywords: Galactosaemia; galactose-1-phosphate uridyltransferase; Irish Travellers; mutation spectrum; allele frequency; population genetics

\section{Introduction}

Transferase-deficient galactosaemia (MIM 230400) is an autosomal recessive condition resulting from defi-

Correspondence: Dr David T Croke, Department of Biochemistry, The Royal College of Surgeons in Ireland, $123 \mathrm{St}$ Stephen's Green, Dublin 2, Republic of Ireland. Tel: 3531402 2280; Fax: 3531402 2467; E-mail: dtcroke@rcsi.ie

Received 2 October 1998; revised 16 December 1998; accepted 19 January 1999 cient activity of galactose-1-phosphate uridyltransferase (GALT), one of the enzymes of the Leloir pathway. Disruption of this pathway, by which galactose is metabolised, leads to the accumulation of various metabolites including galactose, galactose-1-phosphate, galactitol and galactonate. ${ }^{1}$ The clinical sequelae include coagulopathy, vomiting, failure to thrive and jaundice; in untreated infants $E$. coli sepsis (frequently fatal), cirrhosis of the liver, cataract formation and cognitive impairment are also observed. Treatment is 
by means of a galactose-free diet which largely reverses or prevents symptoms in the neonate. However, long term complications are frequently observed which include ovarian dysfunction, developmental delay and a range of neurologic abnormalities. ${ }^{1,2}$

In the majority of cases of transferase-deficient galactosaemia the severe clinical picture is associated with extremely low GALT enzyme activity $(<0.5 \mu \mathrm{mol}$ of substrate converted/per gram of haemoglobin); this is referred to as 'classical' galactosaemia. In addition, individuals are sometimes observed with mild to negligible symptomatology and intermediate levels of enzyme activity associated with 'non-classical' forms of the enzyme such as the Duarte variant. ${ }^{3,4}$

The molecular analysis of transferase-deficient galactosaemia has been made possible by the characterisation of the GALT genomic and transcript sequences. $^{5-8}$ The GALT gene maps to human chromosome $9 \mathrm{p} 13$, is approximately $4 \mathrm{~kb}$ in length and encodes a protein of $43 \mathrm{kDa} .^{7,9,10}$ Considerable work has been done to define the spectrum of GALT mutations giving rise to transferase-deficient galactosaemia. A collaborative database of GALT mutations has recently been established (GALTdb:http//www.ich.bris.ac.uk/galtdb), documenting GALT mutations using GenBank accession number M96264 as the reference sequence. ${ }^{7}$ $\mathrm{Q} 188 \mathrm{R}$ is the most common mutation, occurring at a relative frequency of $60 \%$ in a pan-ethnic galactosaemic patient population, and is due to an A to $G$ transition resulting in a glutamine $(\mathrm{Q})$ to arginine $(\mathrm{R})$ amino-acid substitution at codon $188 .^{7,11,12}$

The incidence of transferase-deficient galactosaemia varies considerably between countries but has been estimated at 1 in 62000 in a large human pan-ethnic study population. ${ }^{13}$ Ireland is of particular interest in this context due to the existence within the population of an endogamous group, known as 'Travellers'. The Travellers are a community who maintain a distinct identity within Irish society, tend to travel in family groups and are commercial/industrial rather than pastoral nomads. ${ }^{14}$ Based upon 1996 data, the Traveller sub-population numbers 4318 households (mean household size $=4.9$ individuals) corresponding to a sub-population size of approximately 21000 in the total Republic of Ireland population of approximately 3.6 million. ${ }^{15}$ In 1996 Traveller families had an average of 3.5 children as compared with 1.8 for the general population. ${ }^{15}$ The incidence of transferase-deficient galactosaemia has recently been estimated at 1 in 700 in the Traveller group and 1 in 23000 in the non-Traveller population in Ireland. ${ }^{16}$ The Travellers' Health Status Study of $1986-87^{17,18}$ estimated that the population numbered 15888 with a median age of 14 years as compared with 27 years in the non-Traveller population. There were 554 live births in 1986 corresponding to a crude birth rate of 34.9 per 1000 (16.6 per 1000 non-Travellers) with a perinatal mortality rate of 28.3 per 1000 (9.9 per 1000 non-Travellers). Several metabolic defects, including glutaric acidaemia type I (MIM 231670) and transferase-deficient galactosaemia are common among them. The origins of the Travellers as a distinct group within the Irish population are the subject of some debate but two main views are extant. The 'migration hypothesis' suggests that the Travellers are derived from a group of nomadic craftspeople who migrated into Ireland from Europe at some point in the past, and who have subsequently maintained genetic isolation and have retained many distinct cultural characteristics. The 'endogenous hypothesis' suggests that the Travellers are descended from a genetic isolate derived from the original population of the island which, over time, has evolved an ethnic identity distinct from that of the general population. ${ }^{14}$

The present study has attempted to obtain more accurate figures for the incidence of classical transferase-deficient galactosaemia and to define the GALT mutation spectrum among patients in both of the Irish population groups. ${ }^{19}$ Knowledge of the genetics of this disease in Ireland will provide a basis for the provision of improved diagnostic and genetic counselling services to the Traveller community and may begin to shed some light on their genetic history.

\section{Subjects and Methods}

\section{Subjects}

Seventy-three children with classical transferase-deficient galactosaemia were detected by newborn screening in the 25 year period from 1972 to 1996. Of these, 56 (including 39 unrelated individuals) were recruited to the present study through the National Newborn Screening Programme, The Children's Hospital, Temple Street, Dublin and blood samples were subjected to genotypic analysis. Ethical approval for the study was obtained from the Ethics Committee of The Children's Hospital. Biochemical diagnosis of the transferasedeficient phenotype was made using a bacterial inhibition assay $^{20}$ in conjunction with the Beutler assay. ${ }^{21}$ Levels of GALT enzyme activity were measured by standard methods in the Department of Clinical Chemistry, Southmead Hospital, Bristol, UK. All patients admitted to the study had a clinical diagnosis of 'classical' galactosaemia; that is galactose1-phosphate uridyltransferase activity of $<0.5 \mu \mathrm{mol}$ of substrate converted/hour per gram of haemoglobin, thus excluding all cases exhibiting the Duarte phenotype. For carrier screening, samples were drawn anonymously from 1000 
unaffected individuals via the National Newborn Screening Programme; this group, consisting of 750 non-Travellers and 250 Travellers, were all drawn from a single calendar year (1996) to minimise bias due to inclusion of siblings. Irish control DNA samples $(n=60)$ were obtained from students in the Medical School of the Royal College of Surgeons in Ireland. Data on number of classical galactosaemic cases diagnosed per year was obtained from the records of the National Newborn Screening Programme.

\section{Methods}

Bloods were collected on to Guthrie cards and, for PCR analysis, a segment of the blood spot (approximately $1 \mathrm{~mm}$ in diameter) was excised from each of the cards to serve as the DNA template.

The Q188R mutation (exon 6) and a Sac I biallelic polymorphism (intron E) were detected by PCR-RFLP methods. ${ }^{12,19,22}$ Selected Q188R homozygotes were confirmed by cycle sequencing ( $\mathrm{fmol}^{\mathrm{TM}}$ cycle sequencing kit, Promega Corp. WI, USA) with radioisotopic detection. In genotyping the Sac I biallelic polymorphism, alleles were scored as Sac $\mathrm{I}(+)$ if the restriction site was present and Sac I(-) if the site was absent. Untyped mutant alleles were screened for sequence alteration in exons $5,7 \& 10$ of the GALT gene by means of single strand conformation polymorphism (SSCP) analysis by the method of Orita $e t a l^{23}$ using PCR product sizes of approximately 200bp to maximise detection efficiency. ${ }^{24}$ The primer pairs used for SSCP analysis were: exon 5, 5'-TTGGGGTTCGCCCTGCCCGTA-3' and 5'-CAAAGCTTCATCACCCCCTCC-3'; exon 7, 5'-TGGGACAGAGGAAATATGCCA-3' and 5'-CCTTTACACACCTCTCTCATG-3'; exon 10, 5'-AGGTGCTAACCTGGATAACTG-3' and 5'-CACATACTGCATGTGAGAGTC-3'. These exons were targeted because they harbour the highest number of reported mutations (GALTdb).

A codon 333 mutation (exon 10) was detected by SSCP and restriction analysis. ${ }^{7}$ Codon 333 of the GALT locus incorporates a $\mathrm{CpG}$ dinucleotide motif and is thus a 'hot spot' for mutation $^{25}$ with three recorded allelic variants, R333W, R333G and R333Q. ${ }^{7,11}$ Mutation at this position, which eliminates a $\mathrm{Hpa}$ II restriction site, was detected by PCR amplification of exon 10 followed by $\mathrm{Hpa}$ II digestion. The nucleotide substitution was characterised by automated fluorescent DNA sequencing (ALFexpress, Pharmacia, Sweden) as a $\mathrm{C}$ to $\mathrm{G}$ transversion, corresponding to the inferred amino-acid substitution R333G. Automated fluorescent DNA sequencing was also used to detect the F194L (exon 7) mutation.

\section{Results}

Surveying newborn screening records for the Irish Republic covering a 25 year period (1972-1996, Table 1), the overall incidence of classical transferasedeficient galactosaemia was found to be 73 cases (31 Traveller, 42 non-Traveller) in 1540585 live births or approximately 1 in 21000 . The only accurate data on annual birth rate among the Traveller community derives from the Travellers' Health Status Study, which documented 554 Traveller live births in 1986. To
Table 1 Ascertainment of classical galactosaemia cases by newborn screening

\begin{tabular}{lcccc}
\hline Year & $\begin{array}{l}\text { Total } \\
\text { births }\end{array}$ & $\begin{array}{l}\text { Total } \\
\text { cases }\end{array}$ & $\begin{array}{l}\text { Traveller } \\
\text { cases }\end{array}$ & $\begin{array}{l}\text { Non-Traveller } \\
\text { cases }\end{array}$ \\
\hline 1972 & 67643 & 3 & 1 & 2 \\
1973 & 67992 & 0 & 0 & 0 \\
1974 & 67784 & 2 & 0 & 2 \\
1975 & 67508 & 1 & 0 & 1 \\
1976 & 68167 & 3 & 2 & 1 \\
1977 & 68436 & 2 & 1 & 1 \\
1978 & 69844 & 2 & 1 & 1 \\
1979 & 72352 & 2 & 1 & 1 \\
1980 & 74388 & 2 & 2 & 0 \\
1981 & 72355 & 3 & 0 & 3 \\
1982 & 70933 & 5 & 0 & 5 \\
1983 & 66815 & 3 & 1 & 2 \\
1984 & 64237 & 4 & 1 & 3 \\
1985 & 62150 & 3 & 1 & 2 \\
1986 & 61425 & 1 & 0 & 1 \\
1987 & 58864 & 5 & 2 & 3 \\
1988 & 54300 & 6 & 3 & 3 \\
1989 & 51659 & 0 & 0 & 0 \\
1990 & 52954 & 1 & 0 & 1 \\
1991 & 52890 & 5 & 2 & 3 \\
1992 & 51584 & 3 & 2 & 1 \\
1993 & 49456 & 8 & 6 & 2 \\
1994 & 47929 & 2 & 1 & 1 \\
1995 & 48530 & 5 & 4 & 1 \\
1996 & 50390 & 2 & 0 & 2 \\
Total & 1540585 & 73 & 31 & 42 \\
\hline & & & &
\end{tabular}

minimise the influence of changes in the population demographics of the Traveller community during this period, estimates of disease incidence among the population groups were made for a 7 year interval centred on 1986 and assuming a constant Traveller birth rate of 550 per annum. On this basis, disease incidence estimates of 1 in 480 and 1 in 30000 were obtained for the Traveller and non-Traveller groups respectively.

The patient cohort recruited to the study was screened for mutations in the GALT gene as described (Table $2 \mathrm{a}$ and $2 \mathrm{~b}$ ). The predominant mutant allele was found to be Q188R, occurring at a relative allele

Table 2(a) Mutant genotype distribution among the transferase-deficient galactosaemic patient cohort presented as genotype frequencies

\begin{tabular}{|c|c|c|c|}
\hline $\begin{array}{l}\text { Mutant } \\
\text { genotype }\end{array}$ & $\begin{array}{l}\text { Total cases } \\
(\mathrm{n}=39)\end{array}$ & $\begin{array}{l}\text { Traveller } \\
\text { cases } \\
(\mathrm{n}=16)\end{array}$ & $\begin{array}{l}\text { Non-Traveller } \\
\text { cases } \\
(\mathrm{n}=23)\end{array}$ \\
\hline Q188R/Q188R & 34 (87.18\%) & $16(100 \%)$ & $18(78.26 \%)$ \\
\hline Q188R/R333G & $1(2.56 \%)$ & $0 \quad(0 \%)$ & $1(4.35 \%)$ \\
\hline Q188R/F194L & $1(2.56 \%)$ & $(0 \%)$ & $1(4.35 \%)$ \\
\hline Q188R/? & $3(7.69 \%)$ & $0 \quad(0 \%)$ & $3(13.04 \%)$ \\
\hline
\end{tabular}

Q188R/? refers to compound heterozygotes for Q188R and an uncharacterised classic galactosaemia allele 
Table 2(b) Mutant genotype distribution among the transferase-deficient galactosaemic patient cohort presented as allele frequencies

\begin{tabular}{|c|c|c|c|}
\hline $\begin{array}{l}\text { Mutant } \\
\text { allele }\end{array}$ & $\begin{array}{l}\text { Total alleles } \\
(\mathrm{n}=78)\end{array}$ & $\begin{array}{l}\text { Traveller } \\
\text { alleles } \\
(\mathrm{n}=32)\end{array}$ & $\begin{array}{l}\text { Non-Traveller } \\
\text { alleles } \\
(\mathrm{n}=46)\end{array}$ \\
\hline Q188R & 73 (93.59\%) & $32(100 \%)$ & $41(89.13 \%)$ \\
\hline R333G & $1(1.28 \%)$ & $0 \quad(0 \%)$ & $1(2.17 \%)$ \\
\hline F194L & $1(1.28 \%)$ & $(0 \%)$ & $1 \quad(2.17 \%)$ \\
\hline Other & $3(3.85 \%)$ & $(0 \%)$ & $3(6.52 \%)$ \\
\hline
\end{tabular}

Other refers to an uncharacterised classical galactosaemia allele or alleles

frequency of $93.6 \%$ overall. Excluding siblings and dividing the patient cohort into Travellers and nonTravellers, Q188R was found to be the sole mutant allele among the Travellers and the majority mutant allele among the non-Travellers $(89.1 \%)$. Of the five non-Q188R mutant alleles in the non-Traveller group, one was $\mathrm{R} 333 \mathrm{G}$ and one $\mathrm{F} 194 \mathrm{~L}$, three alleles remaining uncharacterised (Table 2b).

The allele and heterozygote (carrier) frequencies of Q188R in the Irish population were estimated by anonymous population screening. One thousand individuals, 250 Travellers and 750 non-Travellers, were screened by means of the PCR-RFLP assay for Q188R (Table 3). Among the non-Travellers seven Q188R alleles were detected, corresponding to an allele frequency of 0.005 and a carrier frequency of 0.009 or 1 in 107. Significantly higher values were obtained for the Traveller group: 23 Q188R alleles were detected, corresponding to an allele frequency of 0.046 and a carrier frequency of 0.092 or 1 in 11 .

The Q188R mutation has previously been shown to be in disequilibrium with one of the alleles of the $S a c$ I RFLP (ivs5nt-24g $\rightarrow a$ ) flanking exon 6 of the GALT gene. ${ }^{22}$ The patient group who were homozygous for the Q188R allele, together with a control group $(n=60$ individuals), were screened for the presence or absence of the restriction site (Table 4). The Sac I restriction site was found to be present on all 68 Q188R alleles, both Traveller and non-Traveller. In contrast, among the

Table 3 Determination of Q188R heterozygote (carrier) and allele frequencies in the Traveller and Non-Traveller populations by anonymous screening

\begin{tabular}{lllll}
\hline & $\begin{array}{l}\text { Q188R } \\
\text { heterozygotes }\end{array}$ & Frequency & $\begin{array}{l}\text { Q188R } \\
\text { alleles }\end{array}$ & Frequency \\
\hline $\begin{array}{l}\text { Travellers } \\
(n=250)\end{array}$ & 23 & 0.092 & $23 / 500$ & 0.046 \\
$\begin{array}{l}\text { Non-Travellers } \\
(n=750)\end{array}$ & 7 & $\begin{array}{l}(1 / 11) \\
0.009\end{array}$ & $7 / 1500$ & 0.005 \\
\hline
\end{tabular}

All samples were drawn from infants born in the calendar year 1996 to minimise bias due to the inclusion of siblings
Table 4 Frequency of the Sac I polymorphism on control chromosomes and on chromosomes harbouring the Q188R mutation

\begin{tabular}{lrrr}
\hline Chromosomes & Sac $1(+)$ & \multicolumn{2}{c}{ Sac $I(-)$} \\
\hline Control $(n=120)$ & $106(88.3 \%)$ & $14(11.7 \%)$ \\
Q188R $(n=68)^{\mathrm{a}}$ & $68(100 \%)$ & 0 & $(0 \%)$ \\
Q188R/Traveller $(n=32)$ & $32(100 \%)$ & 0 & $(0 \%)$ \\
$\begin{array}{l}\text { Q188R/Non-Traveller } \\
(n=36)\end{array}$ & $36(100 \%)$ & 0 & $(0 \%)$ \\
\hline
\end{tabular}

${ }^{a}$ These figures refer only to unrelated individuals who were homozygous for Q188R

control group, the Sac I restriction site was present on $88.3 \%$ of chromosomes and absent from $11.7 \%$ of chromosomes. Given that the Duarte allele has a relative frequency of $5-10 \%$ in Europe, it is reasonable to suggest that a proportion of the Sac I(-) control chromosomes harbours the N314D mutation. ${ }^{3,4}$ Our analysis has shown that the R333G and F194L, together with two of the three uncharacterised mutant alleles, were $S a c \mathrm{I}(+)$.

\section{Discussion}

Most commonly, galactosaemia results from a deficiency in galactose-1-phosphate uridyltransferase (GALT) activity, ${ }^{1}$ referred to as transferase-deficient galactosaemia. The incidence of transferase-deficient galactosaemia worldwide is approximately 1 in 62000 live births. ${ }^{13}$ In the Republic of Ireland population we have found that the overall incidence of the disease is significantly higher, at approximately 1 in 21000 . When the incidence figures were broken down for the Traveller and non-Traveller population groups, the incidences were estimated to be 1 in 480 and 1 in 30000 respectively. The incidence estimated for the nonTraveller community is comparable with the figures of 1 in 41938 and 1 in 44000 previously reported for the German and UK populations, ${ }^{13,26}$ but the value of 1 in 480 estimated for the Traveller community is one of the highest incidences of transferase-deficient galactosaemia yet reported. ${ }^{13}$

Among the Traveller group, Q188R was found to be the sole GALT mutation (Table 2b), whilst among nonTravellers it accounted for $89.1 \%$ of mutant alleles. In the non-Traveller group a number of other mutant alleles were detected, including R333G (2.2\%) and F194L (2.2\%). The Q188R carrier frequency was determined in a group of 1000 unrelated individuals (250 Travellers and 750 non-Travellers) by anonymous population screening. Carrier frequencies for Q188R differed by approximately one order of magnitude 
between Travellers and non-Travellers, being 1 in 11 (0.092) and 1 in 107 (0.009) respectively. When the Q188R allele frequency data obtained by population screening were used to predict the frequency of affected individuals (under the assumption of HardyWeinberg equilibrium), values in broad agreement with those calculated from the newborn screening records were obtained ( 1 in 470 Traveller and 1 in 37300 nonTraveller). The similarity between observed and expected values would suggest that the disease incidence among the Travellers reflects the high Q188R allele frequency and that inbreeding may not be a significant factor contributing to the high incidence in that population.

The findings of this study raise a number of interesting questions about the population genetics of galactosaemia and the genetic history of the Travellers in Ireland.

(i) Has Ireland been a centre of diffusion for the Q188R mutation in north-western Europe?

We have demonstrated that Q188R is the predominant allele in the Irish population, having an overall relative allele frequency of $93.6 \%$. Q188R relative allele frequencies have been measured in neighbouring European populations: $77 \%$ in England, $65 \%$ in Germany, $60 \%$ in Austria. ${ }^{27,28}$ It has been suggested by Holton et $a l^{28}$ that the apparent cline of Q188R relative allele frequencies in a south-easterly direction is consistent with Ireland having been the centre of diffusion of this mutation. Our demonstration of the highest Q188R frequencies in Ireland is consistent with this hypothesis. If true, this would directly parallel the independent origin of the R408W haplotype 1.8 Phenylketonuria mutation in Ireland and its spread into mainland Europe. $^{29-31}$

(ii) Why is the Q188R allele frequency significantly higher among the Traveller community in Ireland?

The increased frequency relative to the non-Traveller group may be the result of a founder effect. It is possible that the founders of the modern Irish Traveller population may have harboured mutant alleles (including Q188R) which increased dramatically in frequency over time as the population underwent expansion. That founder effect coupled with rapid expansion can produce substantial increases in allele frequency has been elegantly demonstrated by genetic and genealogic studies of the modern Saguenay population in Quebec. $^{32,33}$ Given a high rate of population expansion and consistently large family size across generations, a mutant allele can reach a frequency of $5 \%$ in the population in five to six generations even if just $2 \%$ of the founder group carried the mutant allele. ${ }^{32}$ Family sizes among the Travellers are consistently large and there is evidence from recent surveys that the Traveller population has undergone considerable expansion; for example, in the 10 years between 1986 and 1996 the Traveller population may have increased in number by as much as 33\% (15888vs about 21000).

(iii) What inferences about the genetic history of the Travellers can be drawn from our observations?

The origins of the Travellers are the subject of some debate with two main hypotheses predominating: the 'migration' and 'endogenous' hypotheses. The fact that Q188R is the sole mutant allele among the Travellers as compared to the non-Traveller group may be the result of a founder effect in the isolation of a small group of the Irish population from their peers as founders of the Traveller sub-population. This would favour the second, endogenous, hypothesis of Traveller origins. Our genotypic data derived from the analysis of the Sac I RFLP (Table 4) may support this. Previous studies have demonstrated that the Q188R mutation is in linkage disequilibrium with the Sac I RFLP in AfricanAmerican, Asian, Caucasian and Latino galactosaemic patients. This has been interpreted to indicate that the Q188R mutation arose once in the history of the modern human population, being spread worldwide by demic diffusion. ${ }^{22}$ We have demonstrated a similar disequilibrium in the Irish population where the Sac I restriction site was found to be present on all Q188R chromosomes. This may suggest that the Q188R mutation, on a Sac I $(+)$ chromosomal 'background', was present in the indigenous population before the Travellers separated and was carried into the Traveller population by its founders. Our findings thus suggest that the modern Traveller sub-population in Ireland had an endogenous origin. Clearly, further consideration of these issues will only be possible on the basis of detailed demographic studies of the Traveller population and of molecular genetic studies of the Irish population, employing perhaps extended autosomal and sex chromosome haplotypes.

\section{Acknowledgements}

Financial support from the Child Health Foundation (The Children's Hospital, Temple Street, Dublin) and from the Research Committee of the Royal College of Surgeons in Ireland is gratefully acknowledged. We are grateful to Dr 
Paul Thornton for permission to include some of the patients under his care in this study. We thank Professor Patrick Cunningham (Department of Genetics, Trinity College, Dublin), Dr Linda Tyfield (University of Bristol) and Dr Peter McWilliam (Royal College of Surgeons in Ireland) for helpful discussions.

\section{References}

1 Segal S, Berry GT: Disorders of galactose metabolism. In: Scriver CR, Beaudet AL, Sly WS, Valle D (eds). The metabolic and molecular bases of inherited disease. 7th ed. McGraw-Hill Inc: New York, 1995, pp 967-1000.

2 West R, Gibson JB: Introduction of new born screening for galactosemia to Arkansas. J Ark Med Soc 1996; 92: 501-504.

3 Beutler E, Baluda MC, Sturgeon P, Day R: A new genetic abnormality resulting in galactose-1-phosphate uridyltransferase deficiency. Lancet 1965; 3: 353-354.

4 Elsas LJ, Dembure PP, Langley S, Paulk EM, Hjelm LN, Fridovich-Keil J: A common mutation associated with the Duarte galactosemia allele. Am J Hum Genet 1994; 54: 1030-1036.

5 Reichardt JKV, Berg P: Cloning and characterization of a cDNA encoding human galactose-1-phosphate uridyltransferase. Mol Biol Med 1988; 5: 107-122.

6 Flach JE, Reichardt JKV, Elsas LJ: Sequence of a cDNA encoding human galactose-1-phosphate uridyltransferase. Mol Biol Med 1990; 7: 365-369.

7 Leslie ND, Immerman EB, Flach JE, Florez M, FridovichKeil JL, Elsas LJ: The human galactose-1-phosphate uridyltransferase gene. Genomics 1992; 14: 474-480.

8 Langley SD, Lai K, Dembure PP, Hjelm LN, Elsas LJ: Molecular basis for Duarte and Los Angeles variant galactosemia. Am J Hum Genet 1997; 60: 366-372.

9 Meera-Khan P, Wijnen LMM, Pearson PL: Assignment of a human galactose-1-phosphate uridyltransferase gene (GALT) to chromosome 9 in human-Chinese hamster somatic cell hybrids. Cytogenet Cell Genet 1978; 22: 207-211.

10 Reichardt JKV: Genetic basis of galactosemia. Hum Mutat 1992; 1: 190-196.

11 Reichardt JKV, Packman S, Woo SLC: Molecular characterization of two galactosemia mutations: Correlation of mutations with highly conserved domains in galactose1-phosphate uridyltransferase. Am J Hum Genet 1991; 49: 860-867.

$12 \mathrm{Ng}$ WG, Xu YK, Kaufman FR et al: Biochemical and molecular studies of 132 patients with galactosemia. Hum Genet 1994; 94: 359-363.

13 Levy HL, Hammersen G: Newborn screening for galactosemia and other galactose metabolic defects. J Pediatr 1978; 92: 871-877.

14 Ni Shuinear S: Irish Travellers, ethnicity and the origins question. In: McCann M, O'Siochain S, Ruane J (eds). Irish Travellers: Culture and Ethnicity. The Institute of Irish Studies. The Queen's University of Belfast: Belfast, 1994, pp 54-77.

15 Central Statistics Office, Ireland: The demographic situation in the Traveller Community in April 1996. Statistical Special Release, March 1998.
16 Badawi N, Cahalane SF, McDonald M et al: Galactosaemia - a controversial disorder. Screening and outcome. Ireland 1972-1992. Ir Med J 1996; 89: 16-17.

17 Barry J, Daly L: The Travellers' Health Status Study. Census of travelling people, November 1986. The Health Research Board of Ireland, 1988.

18 Barry J, Herity B, Solan J: The Travellers' Health Status Study. Vital Statistics of travelling people, 1987. The Health Research Board of Ireland, 1989.

19 Murphy M, Sexton D, O'Neill C, Croke DT, Mayne PD, Naughten ER: Frequency distribution of the Q188R mutation in the Irish galactosaemic population. $J$ Inher Metab Dis 1996; 19: 217-219.

20 Shih VE, Levy HL, Karolkewicz, V et al: Galactosemia screening of newborns in Massachusetts. New Eng J Med 1971; 284: 753-757.

21 Beutler E, Baluda MC: Improved method for measuring galactose-1-phosphate uridyltransferase activity of erythrocytes. Clin Chim Acta 1966; 13: 369-373.

22 Lin HC, Reichardt JKV: Linkage disequilibrium between a $S a c$ I restriction fragment polymorphism and two galactosemia mutations. Hum Genet 1995; 95: 353-355.

23 Orita M, Iwahana H, Kanazawa H, Hayashi K, Sekiya T: Detection of polymorphisms of human DNA by gel electrophoresis as single-strand conformation polymorphisms. Proc Natl Acad Sci USA 1989; 86: 2766-2770.

24 Sheffield VC, Beck JS, Kwitek AE, Sandstrom DW, Stone EM: The sensitivity of Single-Strand Conformation Polymorphism analysis for the detection of single base substitutions. Genomics 1993; 16: 325-332.

25 Cooper DN, Youssoufian $\mathrm{H}$ : The $\mathrm{CpG}$ dinucleotide and human genetic disease. Hum Genet 1988; 78: 151-155.

26 Honeyman MM, Green A, Holton JB: Galactosaemia: results of the British Paediatric Surveillance Unit Study, 1998-90. Arch Dis Child 1993; 69: 339-341.

27 Greber-Platzer S, Guldberg P, Scheibenreiler S et al: Molecular heterogeneity of classical and Duarte galactosemia: mutation analysis by denaturing gradient gel electrophoresis. Hum Mutat 1997; 10: 49-57.

28 Holton JB, Walter JH, Tyfield LA: Galactosaemia. In: Scriver CR, Beaudet AL, Sly WS, Valle D (eds). The metabolic and molecular bases of inherited disease. 8th edition. McGraw-Hill Inc: New York, (in press).

29 Byck S, Morgan K, Tyfield L, Dworniczak B, Scriver CR: Evidence for origin, by recurrent mutation, of the phenylalanine hydroxylase R408W mutation on two haplotypes in European and Quebec populations. Hum Mol Genet 1994; 3: 1675-1677.

30 Eisensmith RC, Goltsov A, O'Neill C et al: Recurrence of $\mathrm{R} 408 \mathrm{~W}$ mutation in the phenylalanine hydroxylase locus in Europeans. Am J Hum Genet 1995; 56: 278-286.

31 O'Neill C, Eisensmith RC, Croke DT, Naughten ER, Cahalane SF, Woo SLC: Molecular analysis of PKU in Ireland. Acta Paediatr 1995; 407 Suppl.: 43-44.

32 Heyer E: Genetic consequences of differential demographic behaviour in the Saguenay region, Quebec. Am J Phys Anthropol 1995; 98: 1-11.

33 Heyer E, Tremblay M: Variability of the genetic contribution of Quebec population founders associated to some deleterious genes. Am J Hum Genet 1995; 56: 970-978. 